\title{
Bradykinin System and Type 2 Diabetes
}

\section{Jagdish N Sharma}

Department of Pharmacology and Therapeutics, Faculty of Pharmacy, Health Sciences Centre, Kuwait University, Kuwait

Diabetes has been implicated as a major risk factor in the development of cardiovascular and renal complications. Previous studies have indicated altered activities of the bradykinin-forming components [1] in diabetic patients and experimental animals. High prevalence rates (25\%) of diabetes have been documented in Kuwaiti population $[2,3]$. Type2 diabetes can lead to hypertension, renal and cardiac complications resulting in high rates of mortality worldwide and in Kuwait as well. Bradykinin (BK), a pharmacologically active polypeptide, is one of kinins which is released in the tissues and body fluids as a result of enzymatic action of kallikreins on kininogens. The two types of kallikrein are tissue kallikrein and plasma kallikrein. Plasma kallikrein is also present in inactive form known as prekallikrein, which can be activated into kallikrein. Tissue kallikrein is mainly expressed in the kidney (urine), glandular tissue, vasculature, [4] heart and brain. It preferentially acts on low molecular weight kininogen substrate to release lysyl-BK. Tissue kallikrein has also been reported to be present in plasma [5,6]. Plasma kallikrein preferentially acts on high molecular weight kininogen substrate to release $\mathrm{BK}$. BK promotes both cardiovascular and renal functions, for example, vasodilation, naturesis and dieresis $[7,8]$. BK is rapidly $(<15 \mathrm{sec})$ inactivated by circulating kinases [9]. BK acts on B1receptor (B1R) and B2 receptor (B2R) [10] to elicit physiological and pharmacological actions. It has been shown previously that type 1 diabetic patients are at a risk of developing nephropathy, having increased renal tissue kallikrein and BK levels [11]. In addition, raised plasma prekallikrein levels in type 1 diabetes have been considered as a risk marker for hypertension and nephropathy [12]. It has been shown that diabetic rats with moderate hyperglycemia, in association with increased urinary kallikrein excretion, resulted in reduced renal vascular resistance (RVR) and increased both renal plasma flow (RPF) and glomerular filtration rate (GFR) [11,12]. The treatment with aprotinin, a kallikrein inhibitor, to these rats increased the RVR and reduced the GFR and RPF $[13,14]$.

The contribution of the renal BK-forming components has been implicated in the renal injury [15] in experimental and type 1 diabetes. The urinary and plasma BK-forming components are comprised of proteins that mediate their effects on vasculature by releasing BK [1517]. It is also known that the tissue kallikrein present in the urine is originating from the kidney and it reflects the renal activity of BK [9] .The present investigation, for the first time, demonstrated that the urinary tissue kallikrein levels were significantly increased in untreated type 2 diabetic patients. In this regard, previous investigations have reported high levels of urinary tissue kallikrein and BK production, in association with RVR,GFR and RPF $[11,12]$ in diabetic rats. Acute administration of aprotinin, a kallikrein inhibitor, and/or B2R antagonist in these hyper filtering diabetic rats reduced the GFR and RPF $[11,12]$ These findings may suggest that thehigh levels of renal tissue kallikrein and BK may mediate renal hyper filtration in diabetes. There was no alteration in the creatinine levels in the present study; however, high plasma prekallikrein levels may suggest the onset of renal abnormalities .In fact, high plasma prekallikrein levels have been documented production, in association with RVR,GFR and RPF $[11,12]$ in diabetic rats. Acute administration of aprotinin, a kallikrein inhibitor, and/or B2R antagonist in these hyper filtering diabetic rats reduced the GFR and RPF [11,12] These findings may suggest that the high levels of renal tissue kallikrein and BK may mediate renal

\section{Publication History:}

Received: April 23, 2016

Accepted: May 28, 2016

Published: May 30, 2016

\section{Keywords:}

Parenteral nutrition, Fish oil, Gastrointestinal surgery, Meta-analysis hyper filtration in diabetes. There was no alteration in the creatinine levels in the present study; however, high plasma prekallikrein levels may suggest the onset of renal abnormalities .In fact, high plasma prekallikrein levels have been documented in type 1 diabetic patients [10]. These investigators suggested that increased plasma prekallikrein level could be a risk factor for hypertension and nephropathy in type 1 diabetes. The present study may also suggest a similar mechanism for developing hypertension and nephropathy in type 2 diabetic patients. Therefore, plasma prekallikrein could be a useful tool for monitoringdiabetic patients for developing hypertension and/or renal abnormalities.

It is of interest to suggest that the early detection of type 2 diabetes based on high urinary kallikrein would be an indicator for future renal abnormality that can be prevented with the treatment. In addition, high plasma prekallikrein activity may serve as an indicator for causing hypertension and left ventricular hypertrophy in diabetic rats [18].

On the other hand, we observed reduced levels of total urinary kininogen in type 2 diabetic patients.This observation might be a reflection on the utilization of kininogen to form BK, a proinflammatory agent as previously reported $[19,20]$. BK1R and BK2R antagonists may normalize the diabetic state in experimentally induced diabetes in mice [21]. Thus, BK antagonist may be targeted for use in diabetic disorders. Moreover, high levels of tissue kallikrein could diminish glucose transport to the tissue [22]. This may also suggest that high levels of tissue kallikrein in diabetic patients might be a predisposing factor in the induction of type 2 diabetes due to the inhibition of glucose transfer to the tissues [22]. Plasma levels of tissue kallikreinhave been reported to be increased in type 2 diabetes as previously reported [23] In the present study however, we also observed high concentrations of plasma tissue kallikrein , which presumably be due to the hyperactivity of the BK-forming system to induce systemic metabolic abnormalities. It has been reported that tissue kallikrein activates B2R directly without BK generation [24]. Furthermore, diabetic rats have been shown to have the glomerular $\mathrm{B} 1 \mathrm{R}$ and B2R expression in the diabetic state [25].

"Corresponding Author: Dr. Jagdish N Sharma, Department of Pharmacology and Therapeutics, Faculty of Pharmacy, Health Sciences Centre, Kuwait University, Kuwait; E-mail: j.n.sharma@hsc.edu.kw

Citation: Sharma JN (2016) Bradykinin System and Type 2 Diabetes. Int J Clin Pharmacol Pharmacother 1: 109. doi: https://doi.org/10.15344/2456$3501 / 2016 / 109$

Copyright: @ 2016 Sharma. This is an open-access article distributed under the terms of the Creative Commons Attribution License, which permits unrestricted use, distribution, and reproduction in any medium, provided the original author and source are credited. 
Recently, alteration in the BK system and nitric oxide has been observed and the type 2 diabetic patients and the treatment with oral hypoglycemic agents improved the abnormality [26, 27].

The present work is in progress to evaluate the influence of antidiabetictreatment on BK-forming components. If our findings are supported by results of other investigators, this would be considered as an extra criterion in the early diagnosis of diabetic risk factors in predicting and preventing nephropathy and retinopathy.

\section{Competing Interests}

The authors declare that they have no competing interests.

\section{References}

1. Leeb-Lundberg LM, Marceau F, Müller-Esterl W, Pettibone DJ, Zuraw BL (2005) International union of pharmacology. XLV. Classification of the kinin receptor family: from molecular mechanisms to pathophysiological consequences. Pharmacol Rev 57: 27-77.

2. Abdella N, Al Arouj M, Al Nakhi A, Al Assoussi A, Moussa M (1998) Noninsulin-dependent diabetes in Kuwait: prevalence rates and associated risk factors. Diabetes Res Clin Pract 42: 187-196.

3. Al-Shoumer KA, Al-Asousi AA, Doi SA, Vasanthy BA (2008) Serum leptin and its relationship with metabolic variables in Arabs with type 2 diabetes mellitus. Ann Saudi Med 28: 367-370.

4. Sharma JN (2006) Role of tissue kallikrein-kininogen-kinin pathways in the cardiovascular system. Arch Med Res 37: 299-306.

5. Rabito SF, Scicli AG, Kher V, Carretero OA (1982) Immunoreactive glandular kallikrein in rat plasma: a radioimmunoassay for its determination. Am J Physiol 242: H602-610.

6. Yayama K, Kunimatsu N, Teranishi Y, Takano M, Okamoto H (2003) Tissue kallikrein is synthesized and secreted by human vascular endothelial cells. Biochim Biophys Acta 1593: 231-238.

7. Katori M, Majima M (2006) A missing link between a high salt intake and blood pressure increase. J Pharmacol Sci 100: 370-390.

8. Sharma JN, Uma K, Yusof AP (1998) Left ventricular hypertrophy and its relation to the cardiac kinin-forming system in hypertensive and diabetic rats. Int J Cardiol 63: 229-235.

9. Sharma JN, Uma K, Noor AR, Rahman AR (1996) Blood pressure regulation by the kallikrein-kinin system. Gen Pharmacol 27: 55-63.

10. Jaffa AA, Durazo-Arvizu R, Zheng D, Lackland DT, Srikanth S, et al. (2003) Plasma prekallikrein: a risk marker for hypertension and nephropathy in type 1 diabetes. Diabetes 52: 1215-1221.

11. Harvey JN, Jaffa AA, Margolius HS, Mayfield RK (1990) Renal kallikrein and hemodynamic abnormalities of diabetic kidney. Diabetes 39: 299-304.

12. Jaffa AA, Rust PF, Mayfield RK (1995) Kinin, a mediator of diabetesinduced glomerular hyperfiltration. Diabetes 44: 156-160.

13. Parappil A, Doi SA, Al-Shoumer KA (2002) Diagnostic criteria for diabetes revisited: making use of combined criteria. BMC Endocr Disord 2: 1.

14. Domke I, Cremer P, Huchtemann M (2000) Therapeutic drug monitoring on COBAS INTEGRA 400--evaluation results. Clin Lab 46: 509-515.

15. Jaffa AA, Rust PF, Mayfield RK (1995) Kinin, a mediator of diabetesinduced glomerular hyperfiltration. Diabetes 44: 156-160.

16. Jaffa AA, Miller DH, Bailey GS, Chao J, Margolius HS, et al. (1987) Abnormal regulation of renal kallikrein in experimental diabetes. Effects of insulin on prokallikrein synthesis and activation. J Clin Invest 80: 16511659.

17. Jaffa AA, Vio C, Velarde V, LeRoith D, Mayfield RK (1997) Induction of renal kallikrein and renin gene expression by insulin and IGF-I in the diabetic rat. Diabetes 46: 2049-2056.

18. Sharma JN, Kesavarao $U$ (2007) Changes in plasma prekallikrein activity, blood pressure, and left ventricular thickness in hypertensive and normotensive diabetic rats. Methods Find Exp Clin Pharmacol 29: 75-78.
19. Weinberg MS, Trebbin WM, Solomon RJ (1986) Urinary kininogen: a possible regulator of kinin formation in normal individuals and subjects with essential hypertension, end-satge renal and liver disease. AdvExp Med Biol 198: 119-125.

20. Weinberg MS, Azar P, Trebbin WM, Solomon RJ (1985) The role of urinary kininogen in the regulation of kinin generation. Kidney Int 28: 975-981.

21. Zuccollo A, Navarro M, Catanzaro O (1996) Effects of B1 and B2 kinin receptor antagonists in diabetic mice. Can J Physiol Pharmacol 74: 586589.

22. Meng K, Haberland GL (1973) In: Haberland, Rohen JW, eds. Kininogenases Kallikrein. F. K. SchattauerVerlag, Stuttgart, USA,75-80.

23. Campbell DJ, Kladis A, Zhang Y, Jenkins AJ, Prior DL, et al. (2010) Increased tissue kallikrein levels in type 2 diabetes. Diabetologia 53: 779 785.

24. Chao J, Yin H, Gao L, Hagiwara M, Shen B, et al. (2008) Tissue kallikrein elicits cardioprotection by direct kinin b2 receptor activation independent of kinin formation. Hypertension 52: 715-720.

25. Christopher J, Jaffa AA (2002) Diabetes modulates the expression of glomerular kinin receptors. Int Immunopharmacol 2: 1771-1779.

26. Sharma JN, Al-Shoumer KA, Matar KM, Al-Gharee HY, Madathil NV (2013) Bradykinin-forming components in Kuwaiti patients with type 2 diabetes. Int J Immunopathol Pharmacol 26: 699-705.

27. Sharma JN, Al-Shoumer K, Matar KM, Madathil NV, Al-Moalem A (2015) Altered activities of kininase II, an angiotensin converting enzyme, prekallikrein, and nitric oxide in Kuwaiti patients with type 2 diabetes. Int $J$ Immunopathol Pharmacol 28: 240-246. 